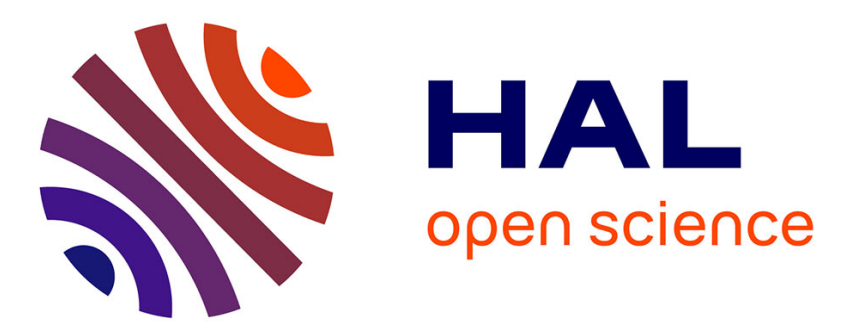

\title{
Barn owl pellets collected in coastal savannas yield two additional species of small mammals for French Guiana
}

Antoine Baglan, Francois Catzeflis

\section{To cite this version:}

Antoine Baglan, Francois Catzeflis. Barn owl pellets collected in coastal savannas yield two additional species of small mammals for French Guiana. Mammalia, 2016, 80 (1), 10.1515/mammalia-2014-0120 . hal-01836192

\section{HAL Id: hal-01836192 \\ https://hal.umontpellier.fr/hal-01836192}

Submitted on 12 Jul 2018

HAL is a multi-disciplinary open access archive for the deposit and dissemination of scientific research documents, whether they are published or not. The documents may come from teaching and research institutions in France or abroad, or from public or private research centers.
L'archive ouverte pluridisciplinaire HAL, est destinée au dépôt et à la diffusion de documents scientifiques de niveau recherche, publiés ou non, émanant des établissements d'enseignement et de recherche français ou étrangers, des laboratoires publics ou privés. 
$1 \quad$ Accepted for publication 22-october-2014

2

3 Short Note for MAMMALIA

Manuscript ID: Mammalia.2014.0120-R1

4

5

6 Barn owl pellets collected in coastal savannas yield two additional species of small mammals

7 for French Guiana.

8

9 Antoine Baglan ${ }^{a}$, François Catzeflis ${ }^{\text {b,* }}$

10

11

$12{ }^{*}$ Corresponding author: François Catzeflis, Université de Montpellier-2, Institut des

13 Sciences de l’Evolution, Case Courrier 064, Place Eugène Bataillon, 34095 Montpellier cedex

14 05, France, e-mail : francois.catzeflis@univ-montp2.fr

15 Tel.: +33672675 412

16

17 Antoine Baglan: SEPANGUY, Maison de la nature de Sinnamary, RN1 PK125, 97315

18 Sinnamary, Guyane française.

19

20 RUNNING TITLE:

21 Small non-volant mammals in French Guianan savannas

22

23

24 ARTICLE INFO

25 Received 26 august 2014; Accepted 22 october 2014; Available online XXX 26 
27 Abstract:

28 A sample of 251 pellets regurgitated by the Barn owl in an old building located in Sinnamary

29 (French Guiana) provided a rare opportunity to get a preliminary inventory of small rodents

30 and opossums living in grassy savannas along the coastal non-forested landscapes of this

31 Guianan region.

32 From a total of 329 specimens of vertebrate remains, we focused on 259 small rodents and

33 opossums which could be positively identified. Two species previously unknown in French

34 Guiana were evidenced: a very small opossum of the genus Cryptonanus and the medium-

35 sized terrestrial rodent Sigmodon alstoni. Whereas Cryptonanus was an unexpected finding so

36 far away from its Amazonian distribution area, the presence of Sigmodon in French Guiana

37 fills a gap between Suriname and Brazilian Amapa where this species is typical of grassy

38 savannas.

39 The species of small mammals most commonly preyed upon by the Barn owls of Sinnamary

40 was a large semi-aquatic rodent, Holochilus sciureus, followed in decreasing order by two

41 sigmodontines typical of non-forested ecosystems: Oligoryzomys fulvescens and

42 Zygodontomys brevicauda.

43

44

45

46 Keywords:

47 Cryptonanus;Holochilus sciureus, Sigmodon alstoni; Coastal savannas; Amazonia

48

49 
51 The analysis of owl pellets contents is a useful tool for providing an inventory of small mammal communities especially in open habitats such as agricultural landscapes or in cerrado-like biotopes (caatinga, savannas, llanos, grassy marshes, ...) in the Neotropics

54 (Rocha et al. 2011; Scheibler and Christoff 2007). The Barn owl (Tyto alba (Scopoli, 1769)) is a specialized predator and most of its preys are small non-volant mammals weighting from 15 to 250 grams. Several recent investigations of Barn owl pellets in Brazil and elsewhere in South America have evidenced the presence of some species of small rodents and opossums which otherwise were very rarely caught by standard trapping methods using live- or snaptraps.

For example, Souza et al. (2010) found two rare dwarf opossums (Gracilinanus agilis Burmeister, 1854; Cryptonanus agricolai (Moojen, 1943)) among 162 pellets collected in the Northeastern Atlantic Forest realm, and those records were new for the coastal region of Pernambuco state. Similarily, Bonvicino and Bezerra (2003) found three rare species (2 small opossums, 1 cerrado mouse) in Barn owl pellets which could not be collected with traps, suggesting that trapping "was either inefficient or was not performed near their specific microhabitats”.

67

This study reports on Barn owl pellets which were collected in an old water-tower in downtown Sinnamary, French Guiana (05²3’ N; 5257’ W) in march 2011 ( 120 pellets) and in september 2013 (131 pellets). Sinnamary is a small city (3100 inhabitants in 2013) at ca. $100 \mathrm{~km}$ north-west from Cayenne; it is located within the coastal northern strip of the country, where non-forested areas, such as agricultural lands, grass and bush savannas, small thickets of trees, grassy swamps and marshes, predominate. The nearest large area of well-drained tropical rainforest starts at 3-4 km south-west from the village, and extends for dozens of km towards the south (the forest locality of Paracou studied by Voss et al. (2001) is only $12 \mathrm{~km}$ from the Barn owl breeding site of Sinnamary). Within a radius of $3 \mathrm{~km}$ from the Barn owl's 
nest, swamp areas and pastures with draining canals constitute most of the area to the northeast, whereas grass and bush savannas intermingled with small thickets dominate to the southeast. The western sides of the water-tower are a mixture of highly degraded secondary forests and of agricultural openings for pastures and various abandoned crops.

The 251 pellets were individually examined for their bony content and a total of 329 vertebrate specimens were isolated. Besides birds (46 individuals), bats (3 skulls of Molossidae) and unidentified murids (21 individuals), the pellets yielded 259 small rodents and opossums which could be identified to species level in most cases. For securing the identification, we relied on comparisons with cleaned skulls of reference specimens (vouchers deposited at Paris MNHN and Geneva MHNG museums) and descriptions and drawings found in Husson (1978), Voss et al. (2001), and Voss and Jansa (2009). All skull and mandibles materials from the owl's pellets have been kept and are avalaible for examination upon writing to the senior author. The following craniodental variables were used and are illustrated and/or defined in Voss et al. (2001) and in Carleton and Musser (1989): BR = Breadth of Rostrum; BZP = Breadth of Zygomatic Plate; LBP = Length of Bony Palate; LIB = Least Interorbital Breadth; LIF = Length of Incisive Foramen; $\mathrm{M}^{1}, \mathrm{M}^{1} \mathrm{M}^{2}, \mathrm{M}^{1} \mathrm{M}^{3}$ : lengths of upper molars; ZB = Zygomatic Breadth.

Craniodental measurements were taken with digital callipers and recorded to the nearest 0.01 $\mathrm{mm}$, but values reported herein are rounded to the nearest $0.1 \mathrm{~mm}$. Univariate statistical tests for comparing measurements between groups included Mann-Whitney nonparametric test, as implemented by the software PAleontological STatistics (PAST: Hammer et al. 2011).

The following taxa were found in the pellets collected at Sinnamary:

- Cryptonanus sp Voss et al. 2005: 10 individuals of that very tiny opossum bring an additional taxon to the mammalian fauna of French Guiana. The identification of these remains (mandibles were almost complete, whereas skulls were highly damaged and resumed 
to the maxillary, palatine and jugal bones) was kindly established by Robert S. Voss (AMNH,

105 New York).

106 The upper molars measurements for 7 adult (all 4 upper molars definitive and erupted)

107 individuals are (mean, minimum, maximum) : $\mathrm{M}^{1} 1.5$ (1.3 to 1.5 ); $\mathrm{M}^{1} \mathrm{M}^{2} 2.8$ (2.8 to 3.0);

$108 \mathrm{M}^{1} \mathrm{M}^{3} 4.2$ (4.1 to 4.4 ); $\mathrm{M}^{1} \mathrm{M}^{4} 4.8$ (4.6 to 4.8); width of $\mathrm{M}^{4}$ (measured as in Voss and Jansa

$1092009) 1.9$ (1.7 to 2.0).

110 The Sinnamary specimens of Cryptonanus appear smaller than C. agricolai, as judged by

111 comparing $\mathrm{M}^{1} \mathrm{M}^{3}$ and $\mathrm{M}^{1} \mathrm{M}^{4}$ lengths values detailed in Voss et al. (2005: Table 5).

112 We refrain from naming to species level our pellets-derived materials of Cryptonanus sp.,

113 pending future analysis on complete vouchered animals that has been recently acquired (two

114 adults weighing 14.5 and 15.5 g: unpublished data).

116 - Marmosa murina (Linnaeus, 1758): 7 individuals, whose upper molars measurements are as

117 follows: $\mathrm{M}^{1} \mathrm{M}^{2} 3.7$ (3.5 to 4.0); $\mathrm{M}^{1} \mathrm{M}^{3} 5.6$ (5.1 to 6.0); $\mathrm{M}^{1} \mathrm{M}^{4} 6.6$ (6.3 to 7.1). Adult $M$. murina

118 weigh ca 41 g (average of 39 individuals caught in French Guiana - unpublished materials).

120 - Philander opossum (Linnaeus, 1758): 1 juvenile (only 1. and 2. upper molars erupted) : $\mathrm{M}^{1}$

$121=3.8 ; \mathrm{M}^{1} \mathrm{M}^{2}=7.8 ;$ P. opossum weighs ca. $220 \mathrm{~g}$ at that age (unpublished data).

123 - Holochilus sciureus Wagner, 1842: this large (adult animals of Guyana average 157 g:

124 Twigg 1965) sigmodontine rodent was the most frequent prey of Tyto alba at Sinnamary, with

125106 individuals (41 \% of all 259 rodents and opossums), most of them being adults (as

126 defined by having three fully erupted molars). The recognition of skull remains of Holochilus

127 sciureus from similar-sized Nectomys rattus (Pelzeln, 1883) is straightforward if molars are

128 still present, as their dental pattern is quite different (see page "A Sampler of Sigmodontine

129 molars” in Myers et al. 2014). When upper molars are lacking (as was the case in 12 skulls),

130 the recognition of Holochilus from Nectomys can be easily reached by measuring the Least 
131 Interorbital Breadth (LIB), as already shown by Husson (1978) for Surinamese animals. In

132 French Guiana, Holochilus sciureus have LIB values smaller than $5.4 \mathrm{~mm}$ whereas Nectomys

133 rattus skulls are larger than $6.1 \mathrm{~mm}$ for that measurement (Table 1).

134

135 - Nectomys rattus: this large (average weight of $177 \mathrm{~g}$ for 23 adults in French Guiana:

136 Catzeflis 2012) terrestrial rodent was represented by 26 individuals (10 \%) and was ranked

137 second after Holochilus when biomass was considered. See above for Holochilus concerning

138 the identification of Nectomys.

139

140 - Oligoryzomys fulvescens (Saussure, 1860) was ranked second for its occurrence (59

141 individuals, or $23 \%$ ) but its contribution to the diet of Tyto alba was less than $4 \%$ of the total

142 biomass, as this terrestrial oryzomyine weighs ca $17 \mathrm{~g}$ (average for 7 adults caught in French

143 Guiana). The identification of this taxon was based upon dental and skull characters described

144 and illustrated in Carleton and Musser (1989). We also compared the values of some selected

145 craniodental measurements (Table 2) in Sinnamary pellets with those measured in vouchered

146 specimens from French Guiana (housed at MNHN and MHNG museums).

148 - Sigmodon alstoni (Thomas, 1881): two individuals of this terrestrial sigmodontine bring an

149 additional taxon to the mammalian fauna of French Guiana. The identification of this

150 medium-sized (average weight is $61.5 \mathrm{~g}$ in Venezuela: Vivas 1986) species is straightforward

151 due to its peculiar upper incisives which are broad and deeply grooved. Voss (1992) provides

152 an excellent description together with detailed figures for the different species of Sigmodon,

153 of which S. alstoni is the one already known in Suriname and Brazilian Amapa.

154 The following craniodental measurements characterize the 2 S. alstoni from Sinnamary owl's

155 pellets: LIB 5.0 \& 5.2; $\mathrm{M}^{1} \mathrm{M}^{2} 4.1$ \& 3.9; $\mathrm{M}^{1} \mathrm{M}^{3}$ 6.0 \& 5.5; ZB 18.9 \& 17.8 . 
- Zygodontomys brevicauda (J.A. Allen and Chapman, 1893): 38 individuals of this terrestrial

158 sigmodontine were identified by comparison with reference materials of French Guianan

159 vouchers, together with the descriptions and drawings available in Voss (1991).

160 Zygodontomys weigh ca 58 g (average for 52 adult specimens caught in French Guiana),

161 therefore this species ranked third by its biomass in the diet of Tyto alba at Sinnamary. The following craniodental measurements are derived from 22 skull-remains : LIB $4.9 \pm 0.3$ (4.4 to 5.4) ; LIF $6.4 \pm 0.6$ (4.7 to 7.1); $\mathrm{M}^{1} \mathrm{M}^{2} 3.3 \pm 0.1$ (3.0 to 3.5); $\mathrm{M}^{1} \mathrm{M}^{3} 4.2 \pm 0.1$ (4.0 to 4.4);

- Mus musculus Linnaeus, 1758: one single damaged skull was identified through the unique murine pattern of the upper molars, and had the following measures: LIB 3.4; $\mathrm{M}^{1} \mathrm{M}^{2}$ 2.7; $\mathrm{M}^{1} \mathrm{M}^{3}$ 3.2; LIF 5.0. Mus musculus caught in French Guiana have an average weight of $14.0 \mathrm{~g}$ (average for 23 adults: unpublished data).

- Rattus norvegicus (Berkenhout, 1769): 6 individuals were identified through qualitative craniodental characters, and selected measurements confirmed their belonging to $R$. norvegicus (see pp. 382-420 in Niethammer and Krapp 1978). Average ( $\mathrm{N}$ from 4 to 6 individuals) and range of values for Sinnamary's materials are: LIB 6.5 (6.2 to 7.2); $\mathrm{M}^{1} \mathrm{M}^{2} 5.4$ (5.3 to 5.5); $\mathrm{M}^{1} \mathrm{M}^{3} 7.1$ (7.0 to 7.2); BZP 4.5 (4.0 to 4.9). We assume that those $R$. norvegicus were not full grown adults whose weight is too large for Tyto alba (Husson (1978) gives ca. $420 \mathrm{~g}$ for the average of 5 adult $R$. norvegicus from Suriname).

- Rattus rattus (Linnaeus, 1758): 2 individuals were identified by comparison with voucher specimens from French Guiana and by examining the characters currently in use for recognizing $R$. rattus from $R$. norvegicus in owl pellets (Corbet and Harris 1991; Niethammer and Krapp 1978). In French Guiana, R. rattus weighs ca. 120 g (average of 35 adult animals: $121 \pm 33 \mathrm{~g}$ - unpublished data). 
- Proechimys guyannensis (E. Geoffroy, 1803) : one single damaged skull was identified

185 through its typical dental pattern and by comparison with voucher materials. This was an

186 adult with all molars erupted, corresponding to a weight of ca. 190 g (Catzeflis and Steiner

187 2000).

188

189

190 Two taxa are new for French Guiana (Catzeflis 2010; Lim 2012): Cryptonanus sp. and

191 Sigmodon alstoni. Before the recent discovery of Cryptonanus in Brazilian Amapa (da Silva

192 et al. 2013), the nearest locality for that diminutive opossum was Crato (07²14’S; 39²3’W)

193 in Brazilian Ceara state for the species C. agricolai (Voss et al. 2005), that is ca. $2000 \mathrm{~km}$

194 south-east from Sinnamary. Da Silva et al. (2013) mention the capture of one specimen of

195 Cryptonanus sp. in a grassy savanna landscape from south-east Amapa, in a locality along

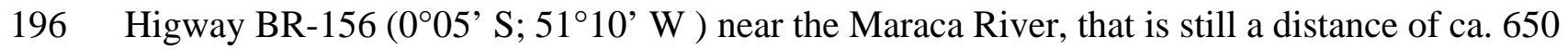

197 km south-east from Sinnamary. In September 2013 two adult Cryptonanus were caught in

198 pitfalls at Sinnamary (unpublished data of F. Catzeflis and B. de Thoisy), and those preserved

199 animals are under study for their identification to species level.

200 The discovery of Sigmodon alstoni in the pellets of the Barn owl from Sinnamary should be

201 no surprise, as the presence in French Guiana of this savanna dweller was suspected by Voss

202 (1992) who wrote that "alstoni should occur in the coastal savannas there " because at that

203 time S. alstoni was known from Suriname (Husson 1978; Williams et al. 1983) and Brazilian

204 Amapa (Carvalho 1962). This species was also recently caught in southern Amapa, in grassy

205 savannas near Ferreira Gomes (da Silva et al. 2013). Sigmodon alstoni is apparently not

206 common around Sinnamary, as only two skulls were found (less than $1 \%$ of all 259 identified

207 small mammals), wheras the similar-sized Zygodontomys accounts for $15 \%$ of the preys. 
At Sinnamary, Barn owls have a large range of prey sizes, from the tiny species around $15 \mathrm{~g}$

210 (Cryptonanus sp.; Mus musculus; Oligoryzomys fulvescens) to the larger taxa around $250 \mathrm{~g}$

211 (juvenile of Philander opossum; Proechimys cayennensis; subadults of Rattus norvegicus).

212 Four species comprise $88 \%$ of all preys and $90 \%$ of the eaten biomass: by decreasing

213 frequency those are Holochilus (157 g on average), Oligoryzomys (17 g), Zygodontomys (58

214 g), and Nectomys (177 g) (Table 3). Clearly, the "food value" (the energy) derived from an

215 Holochilus is much higher than the one provided by an Oligoryzomys, and it is apparently

216 more profitable for owls to select larger prey. With 106 individuals or $41 \%$ of all 259 prey

217 items, Holochilus sciureus was apparently very common in the hunting area of the Barn owls,

218 and it has been shown elsewhere in the Guianan Region that this rodent species might

219 fluctuate in numbers up to high densities (Twigg, 1965). At Sinnamary, where grassy marshes

220 and savannas are the most abundant places within a 3 to $4 \mathrm{~km}$ radius from downtown

221 (unpublished data based on the examination of aerial pictures), the Barn owls secure $78 \%$ of

222 their consumed biomass of non-volant mammals through two species of "large"

223 sigmodontines: Holochilus sciureus and Nectomys rattus (Table 3). But the selection of larger

224 prey-species is not the rule everywhere, as shown by Scheibler and Christoff (2004) in agro-

225 ecosystems of southern Brazil where Tyto alba preyed mostly (82\% of 3618 vertebrates) upon

226 Mus musculus, despite the fact that much larger rodents (Akodon; Necromys) were common in

227 their study area.

228

229 Most authors who have compared inventories of small mammals through pellets analysis and

230 through conventional trapping have concluded that those methods were complementary

231 (Bonvicino and Bezerra 2003; Magrini and Facure 2008; Rocha et al. 2011; Scheibler and

232 Christoff 2007). Thus our results can not be taken as an inventory of the non-volant small

233 mammals living in the grassy savannas, marshes and shrublands around Sinnamary. Future

234 research in these areas there should use conventional trapping as well as pitfalls for improving 
236 French Guiana.

240 Acknowledgements: we thank Elisabeth Cabirou for her technical skills at sorting skulls and 241 bones remains from the Sinnamary owl pellets. Our colleague and friend Robert S. Voss

242 (AMNH, New York) was kind enough to examine and identify the skull remains of

243 Cryptonanus sp. AB thanks the SEPANGUY association for allowing him to work on this

244 project. We thank the environmental services of the municipality of Sinnamary for access to

245 the water-tower building. That research was funded by institutional support of the French

246 CNRS and of the University Montpellier-2. 
References

249

250 Bonvicino, C. R., and A. M. Bezerra. 2003. Use of regurgitated pellets of barn owl (Tyto

251

252 alba) for inventorying small mammals in the cerrado of central Brazil. Stud. Neotrop.

253 Fauna Envir. 38: 1-5.

Carleton, M. D., and G. G. Musser. 1989. Systematic studies of oryzomyine rodents

254

(Muridae, Sigmodontinae): A synopsis of Microryzomys. Bull. Amer. Mus. Nat. Hist. 191: 1-83.

Catzeflis, F. 2010. Liste des Mammifères de Guyane française. Arvicola 19: 39-44.

Catzeflis, F. 2012. A survey of small non-volant mammals inhabiting Wayampi Amerindian houses in French Guiana. Mammalia 76: 327-330.

Catzeflis, F., and C. Steiner. 2000. Nouvelles données sur la morphologie comparée et la distribution des rats épineux Proechimys cuvieri_et P. cayennensis_(Echimyidae: Mammalia) en Guyane française. Mammalia 64: 209-220.

Corbet, G. B., and S. Harris. 1991. The Handbook of British Mammals. Blackwell Scientific Publications, Oxford, UK.

da Silva, C. R., A. C. Moreira Martins, I. J. de Castro, E. Bernard, E. Matos Cardoso, D. Do Santos Lima, R. Gregorin, R. V. Rossi, A. R. Percequillo, and K. d. C. Castro. 2013. Mammals of Amapa state, eastern Brazilian Amazonia: a revised taxonomic list with comments on species distributions. Mammalia 77: 409-424.

de Carvalho, C. T. 1962. Lista preliminar dos mamiferos do Amapa. Pap. Avul. Dept. Zool. Secr. Agric. Sao Paulo 15: 283-297.

Hammer, Ø., D. A. T. Harper, and P. D. Ryan. 2011. PAST: Paleontological Statistics Software Package for Education and Data Analysis. Palaeontologia Electronica 4: 1-9.

272 Husson, A. M. 1978. The mammals of Suriname. E. J. Brill, Leiden.

273 Lim, B. K. 2012. Biogeography of Mammals from the Guianas of South America. Pp. 230- 
and Geography of Recent Neotropical Mammals. . University of Chicago Press, Chicago, Illinois, USA.

Magrini, L., and K. G. Facure. 2008. Barn owl (Tyto alba) predation on small mammals and its role in the control of hantavirus natural reservoirs in a periurban area in southeastern Brazil. Brazil. J. Biol. 68: 733-740.

Myers, P., R. Espinosa, C. S. Parr, T. Jones, G. S. Hammond, and T. A. Dewey. 2014. The Animal Diversity Web (online), http://animaldiversity.ummz.umich.edu/collections/mammal_anatomy/sigmodontine_t eeth/. Accessed 13 may, 2014

Niethammer, J., and F. Krapp. 1978. Handbuch der Säugetiere Europas. Akademische Verlagsgesellschaft, Wiesbaden, Germany.

Rocha, R. G., E. Ferreira, Y. L. R. Leite, C. Fonseca, and L. P. Costa. 2011. Small mammals in the diet of barn owls, Tyto alba (Aves: Strigiformes) along the mid-Araguaia river in central Brazil. Zoologia (Curitiba) 28: 709-716.

Scheibler, D. R., and A. U. Christoff. 2004. Small mammals in the diet of barn owls (Tyto alba) in agroecosystems of southern Brazil. Ornitol. Neotrop. 15: 65-70.

Scheibler, D. R., and A. U. Christoff. 2007. Habitat associations of small mammals in southern Brazil and use of regurgitated pellets of birds of prey for inventorying a local fauna. Brazil. J. Biol. 67: 619-625.

Souza, D. P., P. H. Asfora, T. C. Lira, and D. Astua. 2010. Small mammals in Barn Owl (Tyto alba - Aves, Strigiformes) pellets from Northeastern Brazil, with new records of Gracilinanus and Cryptonanus (Didelphimorphia, Didelphidae). Mammalian Biol. 75: $370-374$.

Twigg, G. I. 1965. Studies on Holochilus sciureus berbicensis, a cricetine rodent from the coastal region of British Guiana. Proc. Zool. Soc. London 145: 263-283.

Vivas, A. M. 1986. Population biology of Sigmodon alstoni (Rodentia: Cricetidae) in the Venezuelan Llanos. Rev. Chilena Hist. Nat. 59: 179-191. 
Voss, R. S. 1991. An introduction to the Neotropical muroid rodent genus Zygodontomys. Bull. Amer. Mus. Nat. Hist. 210: 1-113.

304 Voss, R. S. 1992. A revision of the South American species of Sigmodon (Mammalia:

305 Muridae) with notes on their natural history and biogeography. Am. Mus. Novit. 3050:

306 1-56.

307 Voss, R. S., and S. A. Jansa. 2009. Phylogenetic relationships and classification of didelphid 308 marsupials, an extant radiation of New World metatherian mammals. Bull. Amer. Mus. Nat. Hist. 322: 1-177.

Voss, R. S., D. P. Lunde, and S. A. Jansa. 2005. On the contents of Gracilinanus Gardner and Creighton, 1989, with the description of a previously unrecognized clade of small didelphid marsupials. Amer. Mus. Novit. 3482: 1-34.

Voss, R. S., D. P. Lunde, and N. B. Simmons. 2001. The mammals of Paracou, French Guiana: A Neotropical lowland rainforest fauna. Part 2: Nonvolant species. Bull. Suriname expeditions. VII. Records of mammals from central and southern Suriname. 
324 Table 1: Measurements (mm) of four craniodental variables in adult Holochilus sciureus and 325 Nectomys rattus

326

\begin{tabular}{|l|l|l|l|}
\hline & Holochilus sciureus & $P$-value & Nectomys rattus \\
\hline LIB & $4.8 \pm 0.3(4.0-5.4) 91$ & $<0.001$ & $6.7 \pm 0.4(6.1-7.7) 25$ \\
\hline $\mathrm{M}^{1}$ & $3.0 \pm 0.1(2.6-3.3) 90$ & NS & $3.0 \pm 0.1(2.8-3.2) 10$ \\
\hline $\mathrm{M}^{1} \mathrm{M}^{2}$ & $4.9 \pm 0.2(4.4-5.3) 92$ & $\mathrm{NS}$ & $4.9 \pm 0.2(4.5-5.3) 11$ \\
\hline ZB & $20.1 \pm 1.3(17.9-22.8) 39$ & $\mathrm{NS}$ & $21.0 \pm 2.1(17.1-24.1) 8$ \\
\hline
\end{tabular}

328 Summary statistics include the sample mean \pm one standard deviation, the observed range (in

329 parentheses), and the sample size. P-values for Mann-Whitney tests.

330 Abbreviations: LIB = Least Interorbital Breadth; $\mathrm{M}^{1}, \mathrm{M}^{2}$ : lengths of upper molars; $\mathrm{ZB}=$

331 Zygomatic Breadth; NS = non significant at $\mathrm{p}=0.05$ level 
334 Table 2: Measurements (mm) of four craniodental variables in Oligoryzomys fulvescens skulls 335 from Sinnamary pellets and in adult voucher specimens from French Guiana.

336

\begin{tabular}{|l|l|l|l|}
\hline & $\begin{array}{l}\text { Sinnamary owl's } \\
\text { pellets }\end{array}$ & P- & \\
\hline LIB & $3.6 \pm 0.2(3.3-4.1) 35$ & NS & $3.6 \pm 0.2(3.3-4.2) 29$ \\
\hline $\mathrm{M}^{1} \mathrm{M}^{3}$ & $3.0 \pm 0.1(2.7-3.1) 38$ & $\mathrm{NS}$ & $3.0 \pm 0.1(2.8-3.2) 29$ \\
\hline $\mathrm{BR}$ & $4.3 \pm 0.3(3.9-5.1) 26$ & $\mathrm{NS}$ & $4.3 \pm 0.3(3.8-5.1) 26$ \\
\hline LBP & $3.9 \pm 0.1(3.6-4.2) 23$ & NS & $3.8 \pm 0.2(3.0-4.1) 25$ \\
\hline
\end{tabular}

337

338 Summary statistics include the sample mean \pm one standard deviation, the observed range (in parentheses), and the sample size. P-values for Mann-Whitney tests.

340 Abbreviations: LIB = Least Interorbital Breadth; $\mathrm{M}^{1} \mathrm{M}^{3}$ : lengths of upper molars; $\mathrm{BR}=$

341 Breadth of Rostrum; LBP = Length of Bony Palate; NS = non significant at $\mathrm{p}=0.05$ level

342 Reference specimens examined for Oligoryzomys fulvescens: MNHN-1981-183, 1986-174,

$343175,177,480,482,956$ to 959, 962 to 966, 968 to 973, 975; 1998-673; MHNG-1979.04;

344 Catzeflis V-1007, V-1899. 
347 Table 3: Relative contribution of each prey species to energy intake of the Barn owl, as

348 expressed by the product of the sample size by the average weight of an individual. The total

349 weight of all 259 ingested preys is $27^{\prime} 475 \mathrm{~g}$, and energy intake is represented by the weight.

350

\begin{tabular}{|l|c|c|c|c|}
\hline & Weight (ref.) & N ind. & \% ind. & $\%$ energy \\
\hline Cryptonanus sp. & $15(\mathrm{a})$ & 10 & 3,9 & 0,5 \\
\hline Marmosa murina & $41(\mathrm{a})$ & 7 & 2,7 & 1,0 \\
\hline Philander opossum & $220(\mathrm{a})$ & 1 & 0,4 & 0,8 \\
\hline Holochilus sciureus & $157(\mathrm{~b})$ & 106 & 40,9 & 60,6 \\
\hline Nectomys rattus & $177(\mathrm{c})$ & 26 & 10,0 & 16,7 \\
\hline Oligoryzomys fulvescens & $17(\mathrm{a})$ & 59 & 22,8 & 3,7 \\
\hline Sigmodon alstoni & $61,5(\mathrm{~d})$ & 2 & 0,8 & 0,4 \\
\hline Zygodontomys brevicauda & $58(\mathrm{a})$ & 38 & 14,7 & 8,0 \\
\hline Mus musculus & $14(\mathrm{a})$ & 1 & 0,4 & 0,1 \\
\hline Rattus norvegicus & $300(\mathrm{a})$ & 6 & 2,3 & 6,6 \\
\hline Rattus rattus & $120(\mathrm{a})$ & 2 & 0,8 & 0,9 \\
\hline Proechimys cayennensis & $190(\mathrm{e})$ & 1 & 0,4 & 0,7 \\
\hline
\end{tabular}

351

352 Abbreviations: (ref.) = reference for the average weight. $\mathrm{a}=$ unpublished data from wild-

353 caught animals in French Guiana; b = Twigg (1965); c = Catzeflis (2012); d = Vivas (1986); e

$354=$ Catzeflis and Steiner (2000). 